\title{
La respuesta de Europa a la crisis ¿Está España protegida?
}


LA FUNDACIÓN CENTRO DE ESTUDIOS ANDALUCES ES UNA ENTIDAD DE CARÁCTER CIENTÍFICO Y CULTURAL, SIN ÁNIMO DE LUCRO, ADSCRITA A LA CONSEJERÍA DE LA PRESIDENCIA, ADMINISTRACIÓN PÚBLICA E INTERIOR DE LA JUNTA DE ANDALUCÍA. ENTRE NUESTROS OBJETIVOS FUNDACIONALES SE ESTABLECEN EL FOMENTO DE LA INVESTIGACIÓN CIENTÍFICA, LA GENERACIÓN DE CONOCIMIENTO SOBRE LA REALIDAD SOCIAL, ECONÓMICA Y CULTURAL DE ANDALUCÍA Y LA DIFUSIÓN DE SUS RESULTADOS EN BENEFICIO DE TODA LA SOCIEDAD.

NUESTRO COMPROMISO CON EL PROGRESO DE ANDALUCÍA NOS IMPULSA A LA CREACIÓN DE ESPACIOS DE INTERCAMBIO DE CONOCIMIENTO CON LA COMUNIDAD CIENTIIFICA E INTELECTUALY CON LA CIUDADANÍA EN GENERAL, Y A LA COLABORACIÓN ACTIVA CON LAS INSTITUCIONES PÚBLICAS Y PRIVADAS QUE INFLUYEN EN EL DESARROLLO DE LA COMUNIDAD AUTÓNOMA.

LA COLECCIÓN ACTUALIDAD FORMA PARTE DEL CATÁLOGO DE PUBLICACIONES CIENTIIFICAS DE LA FUNDACIÓN Y ESTÁ DESTINADA TANTO AL LECTOR ESPECIALIZADO COMO A LA OPINIÓN PÚBLICA EN GENERAL. CADA UNA DE SUS EDICIONES SE ESTRUCTURA COMO INFORMES MONOGRÁFICOS PARA EL FOMENTO DE LA REFLEXIÓN Y EL ANÁLISIS SOBRE ASPECTOS DE RELEVANCIA PARA LA SOCIEDAD ANDALUZA DEL SIGLO XXI.

LAS OPINIONES PUBLICADAS POR LOS AUTORES EN ESTA

COLECCIÓN SON DE SU EXCLUSIVA RESPONSABILIDAD.

(c) Del texto: sus autores, 2020

(c) De la edición: Fundación Pública Andaluza

Centro de Estudios Andaluces, marzo de 2020

Bailén 50, 41001 Sevilla.

Tel.: 955055 210. Fax: 955055211

www.centrodeestudiosandaluces.es

Depósito Legal: SE-1688-05

I.S.S.N.: 1699-8294

Ejemplar Gratuito. Prohibida su venta. 
La respuesta de Europa a la crisis

¿Está España protegida?

Carmen Pérez López

Universidad de Sevilla 


\section{ÍNDICE}

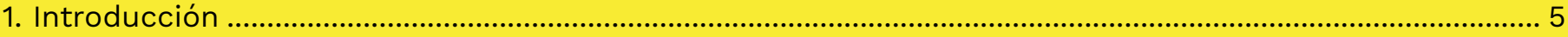

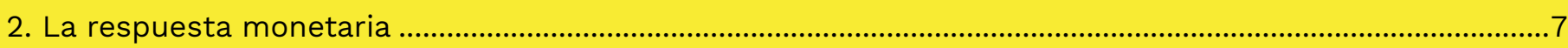

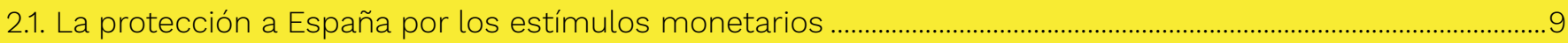

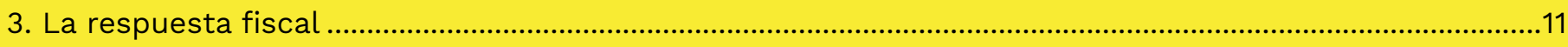

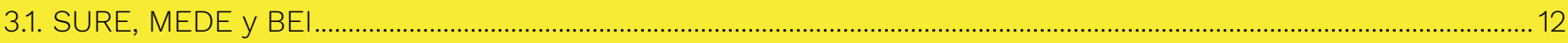

3.2. Marco financiero plurianual y el Fondo de reconstrucción europeo ..........................................................................13

3.3. La protección a España por los estímulos fiscales.....................................................................................................15

4. ¿Será suficiente?

4.1. La banca como problema

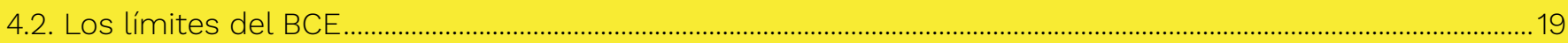




\section{Introducción}

El objetivo de este artículo es describir en qué consiste la respuesta que Europa ha dado a la crisis provocada por el COVID-19. Pero no se queda sólo en la descripción de las iniciativas puestas en marcha, sino que también valora en qué medida constituyen un paraguas de protección para España, dada su desfavorable situación financiera de partida y dado el enorme impacto que está suponiendo esta crisis para la economía española.

En el análisis de las iniciativas que se han tomado se consideran tanto las que conciernen al ámbito monetario, a través del Banco Central Europeo, como las de naturaleza fiscal, impulsadas desde la Comisión Europea. Esta doble actuación marca una diferencia radical con la crisis financiera de 2008. En esta ocasión se han adoptado una serie de medidas desde el ámbito fiscal de importante calado y trascendencia. En gran parte, esto ha sido posible gracias a la gobernadora del BCE, Christine Lagarde, que ha mantenido una postura firme y exigente para que se complementaran los estímulos monetarios con otros de carácter fiscal. Igualmente, ha sido decisivo el cambio de actitud de la canciller alemana, Angela Merkel, que ha entendido que de no acometerlos estaría en serio peligro la continuidad del proyecto europeo.

\section{Gráfico 1. La protección de Europa a España}

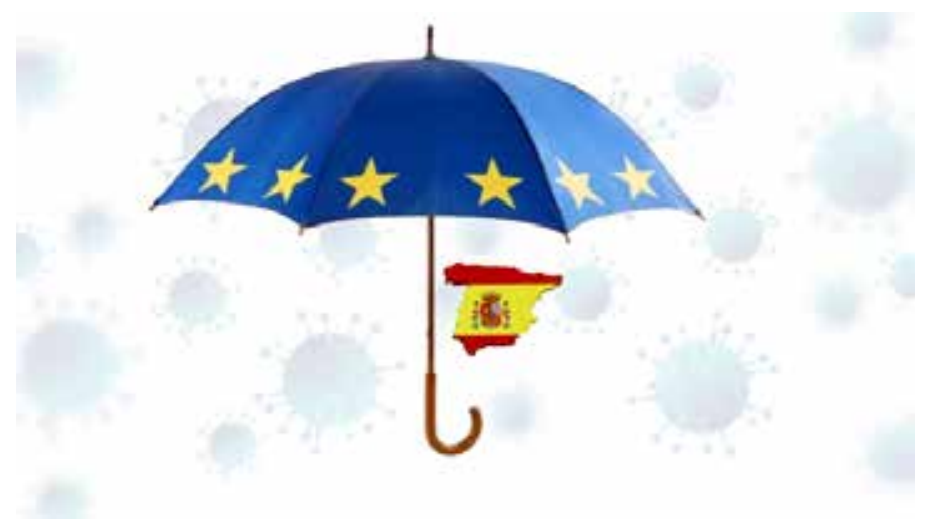

Fuente: elaboración propia.

\begin{abstract}
La exposición atenderá las diversas facetas de esta respuesta por un orden cronológico, tal y como se han ido tomando. Las primeras iniciativas partieron del BCE por la mayor facilidad que tiene esta entidad para tomar decisiones. Su carácter técnico e independiente le permiten actuar con rapidez, lejos de la lentitud que supone llegar a acuerdos en el ámbito fiscal, tanto por la multiplicidad de actores intervinientes como porque todos ellos, además, están fuertemente condicionados por sus respectivas políticas nacionales. En ambos casos se analiza cómo protegen particularmente a España, y será al final cuando se realice una valoración conjunta de estos dos paraguas protectores.
\end{abstract}

\section{Gráfico 2. La doble protección de Europa: monetaria y fiscal}

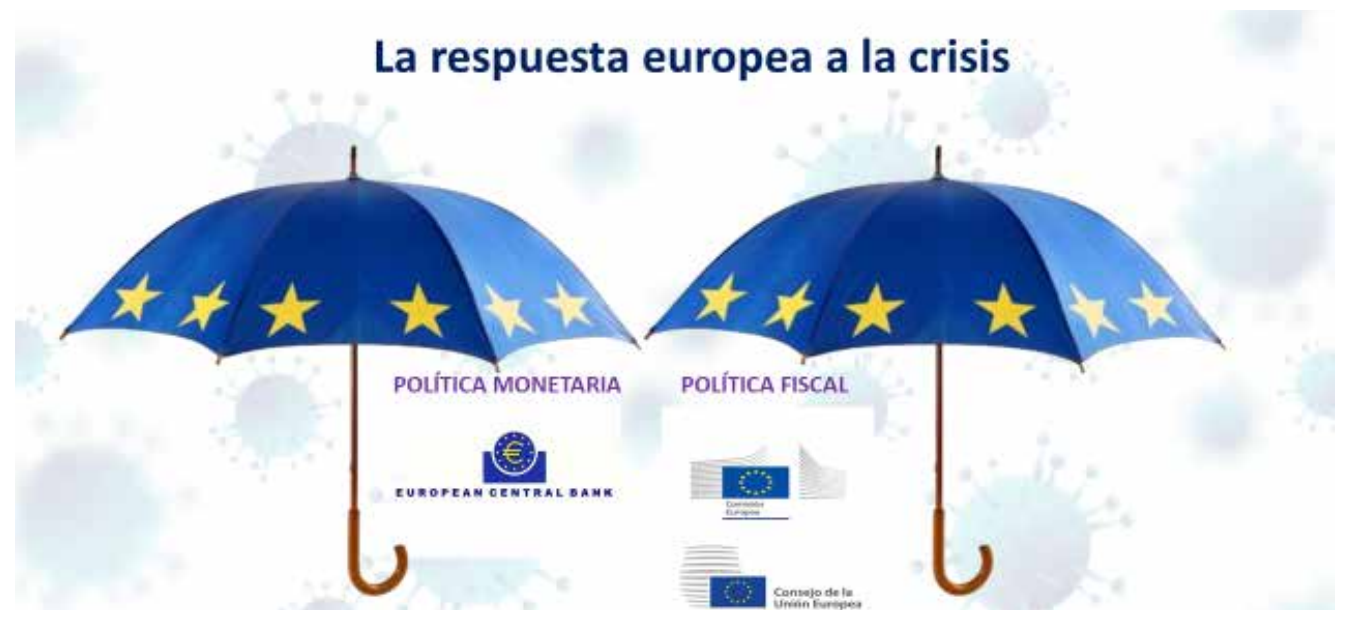

Fuente: elaboración propia. 


\section{La respuesta monetaria}

La tabla 1 recoge las decisiones del Consejo de Gobierno del BCE desde que comenzó la pandemia en Europa, a mediados de marzo, hasta finales de agosto. A fecha de hoy, 12 de octubre, esa tabla sigue estando vigente porque en la última reunión, celebrada el 10 de septiembre no se tomó ninguna medida adicional ni se modificaron las que estaban en marcha'.

De este cuadro pueden destacarse estas cuatro líneas de actuación:

\section{Asset Purchase Programme (APP) ${ }^{2}$}

Este programa, uno de los paquetes más relevantes dentro de las medidas tomadas por el BCE a causa de la anterior crisis, seguía abierto por las reinversiones de las cantidades procedentes de los activos adquiridos a los que les llegaba el vencimiento. Además, en noviembre de 2019, se reactivó, determinando compras netas adicionales de 20.000 millones de euros al mes. Con la pandemia, en marzo de 2020, el BCE tomó la decisión de incrementar las compras hasta diciembre por 120.000 millones adicionales y permitir que entre los activos elegibles estuvieran los pagarés de empresa.

\section{Pandemic Emergency Purchase Programme (PEPP)}

Un nuevo programa de compras por la pandemia. Con él, el BCE pretende alcanzar un volumen de compras de 1,35 billones de euros: tras los 750.000 millones iniciales que se fijaron en marzo, se añadieron 600.000 millones más en junio. Además de su extraordinario importe, este nuevo programa es de mayor relevancia porque nace con menos condicio-

\footnotetext{
1 Mucho habría que discutir y que cuestionar sobre la política monetaria desarrollada, no sólo en esta crisis sino también en la pasada. Estar conforme en su aplicación en momentos desesperados, no debería eludir una revisión profunda de las circunstancias que han llevado está aquí, y entre ellas y fundamentalmente la configuración del sistema financiero.

2 Incluye el programa de compras del sector empresarial (CSPP), el programa de compras del sector público (PSPP), el programa de compra de valores respaldados por activos (ABSPP) y el tercer programa de compra de bonos garantizados (CBPP3).
}

nantes que los anteriores, en cuanto a los tipos de activos, distribución en el tiempo y cantidad dedicada a cada uno de los países (esto es, la posibilidad de saltarse la clave de capital, de la que al final del artículo se hace referencia). Las compras se extenderán hasta finales de junio de 2021 y las reinversiones al menos hasta final de 2022.

\section{Líneas de swaps en dólares}

Reactivación de estas líneas con la Reserva Federaly con otros bancos centrales importantes.

\section{La banca como solución}

Si en la antigua crisis la banca era el problema, ahora se ha confiado en que contribuya a la solución, porque su alta capilaridad le permite llegar rápidamente a atender al tejido empresarial. Se han tomado medidas en dos frentes complementarios:

- Por una parte, a la banca se le ha ampliado, extendido y mejorado las líneas de liquidez, elevando también su retribución -al $1 \%$ - en alguna de ellas. Al mismo tiempo, se han relajado las condiciones - los colaterales elegibles - para que pueda acceder a las mismas con mayor facilidad.

- Por otra parte, se ha rebajado el listón regulatorio, suavizando las exigencias que la reforma de Basilea había impuesto ${ }^{3}$ tras la anterior crisis.

Simultáneamente a la mejora de las condiciones para que desarrollen su actividad, y para evitar lo que pasó en la crisis financiera pasada, en la que los bancos ante la incertidumbre no prestaban («Se puede llevar el caballo al río, pero no puede obligársele a beber»), los Estados - de forma coordinada por Europahan asumido la mayor parte del riesgo de las operaciones que han concedido desde que se inició la pandemia. En España, este aval ha sido concedido principalmente por el Instituto de Crédito Oficial, ICO.

\footnotetext{
3 Al igual que la política monetaria, eliminar todos los refuerzos regulatorios que se habían hecho producto de aprendizaje de la anterior crisis es una solución a la desesperada. A cambio, se les ha «recomendado» no repartir dividendos, para incrementar su solvencia. De igual forma, se les ha «animado» a fusionarse entre ellos, modificando la legislación para que les resulte más favorable hacerlo.
} 
Tabla 1. Las medidas del BCE a causa de la pandemia

\begin{tabular}{|c|c|}
\hline & March 2020 \\
\hline \multirow{2}{*}{$\begin{array}{l}\text { Asset } \\
\text { pur- } \\
\text { chases }\end{array}$} & $\begin{array}{l}\text { Asset purchase programme } \\
\text { (APP) envelope extended } \\
\text { by EUR } 120 \text { bn in } 2020 \\
\text {-in addition to ongoing APP } \\
\text { purchases of EUR } 20 \text { bn per } \\
\text { month and reinvestments } \\
\text {-NFC commercial paper } \\
\text { made eligible }\end{array}$ \\
\hline & $\begin{array}{l}\text { Pandemic emergency pur- } \\
\text { chase programme (PEPP) } \\
\text { launched } \\
\text {-EUR } 750 \text { bn envelope until } \\
\text { at least Dec. } 2020 \\
\text {-flexible allocation across } \\
\text { time, assets, countries }\end{array}$ \\
\hline
\end{tabular}

\begin{tabular}{|c|c|c|}
\hline \multirow{3}{*}{$\begin{array}{l}\text { Len- } \\
\text { ding } \\
\text { pro- } \\
\text { gram- } \\
\text { mes* }\end{array}$} & $\begin{array}{l}\text { Conditions for targe- } \\
\text { ted lending programme } \\
\text { (TLTRO-III) eased } \\
\text {-borrowing rate - } 25 \text { to } \\
\text { - } 75 \text { bps (Jun. } 2020 \text { to Jun. } \\
\text { 2021), depending on lending } \\
\text { performance } \\
\text {-borrowing allowances rai- } \\
\text { sed, etc. }\end{array}$ & $\begin{array}{l}\text { Further easing of TLRO- } \\
\text { III conditions } \\
\text {-borrowing rate - } 50 \text { to } \\
\text {-100 bps (Jun. } 2020 \text { to } \\
\text { Jun. 2021), depending on } \\
\text { lending performance } \\
\text {-further easing of terms } \\
\text { and conditions }\end{array}$ \\
\hline & $\begin{array}{l}\text { Additional longer-term } \\
\text { refinancing operations } \\
\text { (LTROs) } \\
\text {-facilitating switch into } \\
\text { TLTRO-III }\end{array}$ & $\begin{array}{l}\text { Pandemic emergency } \\
\text { longer-term operations } \\
\text { (PELTROs) introduced } \\
-7 \text { ops. from May } 2020, \\
\text { maturing by Sep. } 2021 \\
\text {-interest rate of -25 bps }\end{array}$ \\
\hline & & $\begin{array}{l}\text { Temporary easing of co- } \\
\text { llateral requirements } \\
\text {-reduction of collateral } \\
\text { valuation haircuts } \\
\text {-mitigation of impact of } \\
\text { potential rating changes } \\
\text {-wider eligibility of credit } \\
\text { claims } \\
\text {-eligibility of Greek sovere- } \\
\text { ign debt instruments }\end{array}$ \\
\hline
\end{tabular}

EUR swap lines reactivated -with the central bank of Denmark

\section{Swap/ \\ repo \\ lines US dollar swap lines reactivated \\ -with Federal Reserve and other major central banks, USD provision through liqui- dity swap line -daily 7-day and weekly 84- day operations}

Temporary capital, liquidity and operational relief -facilitating use of capital

Superand liquidity buffers

visory -flexible prudential

treatment of loans backed

sures by public support measures and mitigation of procyclicality in accounting -recommendation against dividend payments

\section{EUR swap lines set up} -with central banks of croatia and Bulgaria
Temporary reduction in capital requirements for market risk

\section{PEPP expanded}

-envelope increase by EUR 600 bn to EUR 1,350

bn and extension by 6 months until at least Jun. 2021

-reinvestments at least until end of 2022
EUREP repo facility and EUR repo line set up -new Eurosystem repo facility to provide euro liquidity to non-euro area central banks (EUREP) -repo line with central bank of Romania set up

Frequency of 7-day USD operations reduced -to three per week
EUR repo lines set up -with central banks of Albania, Hungary, Serbia, Republic of North Macedonia and San Marino

Frequency of 7-day USD operations reduced -to one per week as of 1 September

\author{
Further guidance \\ - guidance against \\ dividend payments \\ and for moderation in \\ remuneration \\ -clarification on restora- \\ tion of capital/liquidity \\ buffers and supervisory \\ expectations on addres- \\ sing debtor stress
}




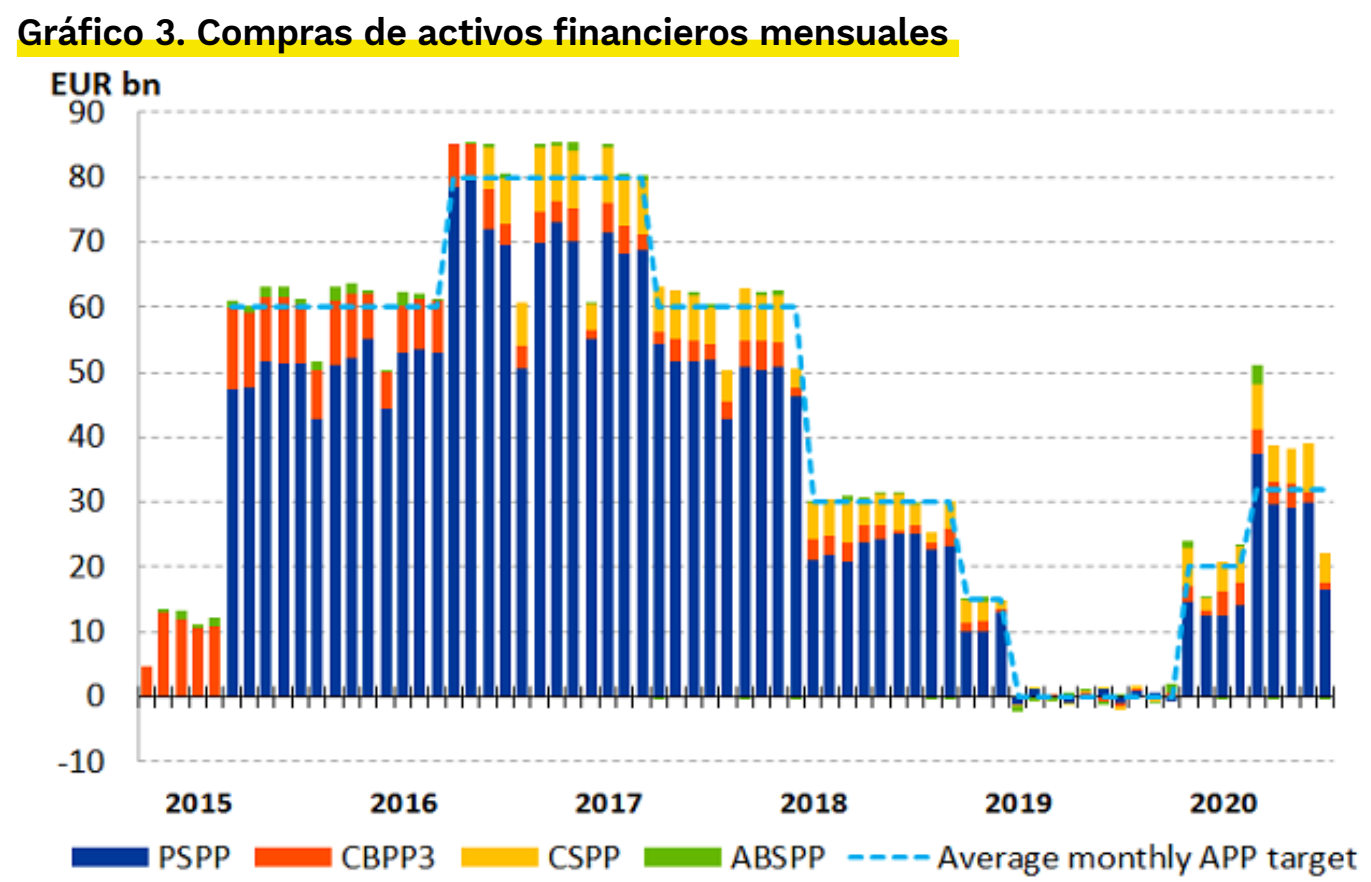

Fuente: Banco Central Europeo.

En definitiva, con esta pandemia se ha reclutado a la banca para que sea parte de la solución, pero, como se analizará al final del artículo, también esta apuesta puede convertirse en un problema.

Para terminar, conviene poner en perspectiva esta respuesta para tomar conciencia de su dimensión. En el gráfico 3 se detalla las compras mensuales en los distintos programas establecidos desde mediados de 2014, cuando el BCE se abrió a utilizar este instrumento no convencional para incrementar la oferta monetaria. El más importante, en azul, es el programa de compras de activos financieros públicos (el PSPP, dentro del APP) mencionado anteriormente. El volumen de compras llegó a superar los 80.000 millones mensuales. Puede observarse cómo el BCE comenzó a disminuir las compras netas (tapering) hasta paralizarlas. Pero duró poco tiempo ya que se reactivó en noviembre de 2019, como se señaló también anteriormente: el BCE tuvo que volver a los estímulos porque la economía estaba desacelerándose, con Alemania, Italia o Francia con crecimientos mínimos o incluso en recesión técnica. En España había signos de desaceleración pero, de momento al menos, escapaba a ese comportamiento. La pandemia viene a llover sobre mojado.

El gráfico 4 considera dichas compras, pero de forma acumulada. Como en todo momen- to el BCE ha establecido la reinversión de toda cantidad procedente de los bonos que fueran venciendo, actualmente la cantidad en manos de este organismo a través de los diferentes programas iniciados por la anterior crisis supera los 2,8 billones de euros.

Y, por último, el gráfico 5 donde se detallan las compras de los distintos bancos centrales, durante la anterior y la nueva crisis. Como puede fácilmente observarse, es espectacular el volumen de compras establecido tras la pandemia. Si desde 2014, y durante más de cinco años, el BCE compró 2,8 billones de euros, ahora en 9 meses va a comprar 1,5 billones de euros, además de mantener la reinversión de todo el volumen tanto del anterior programa como del nuevo. La respuesta, por tanto, ha sido descomunal. Además, no se descarta que en la reunión del Consejo de Gobierno de diciembre se amplíe aún más el PEPP en otros 500.000 millones de euros ${ }^{4}$.

\footnotetext{
4 La política monetaria desarrollada por el Banco Central Europeo (BCE) trae a la memoria una de las increíbles historias del barón de Münchhausen. Concretamente aquélla en que contaba que había sido capaz salir de un pantano cenagoso donde había quedado atrapado con su caballo sin más que tirar de sus propios cabellos. Con los programas de compras de activos nos hemos comprado una ingente cantidad de bonos a nosotros mismos. Al igual que la hazaña del barón Münchhausen es del todo imposible, con el esfuerzo monetario sólo no es suficiente.
} 
Gráfico 4. Compras de activos financieros acumuladas

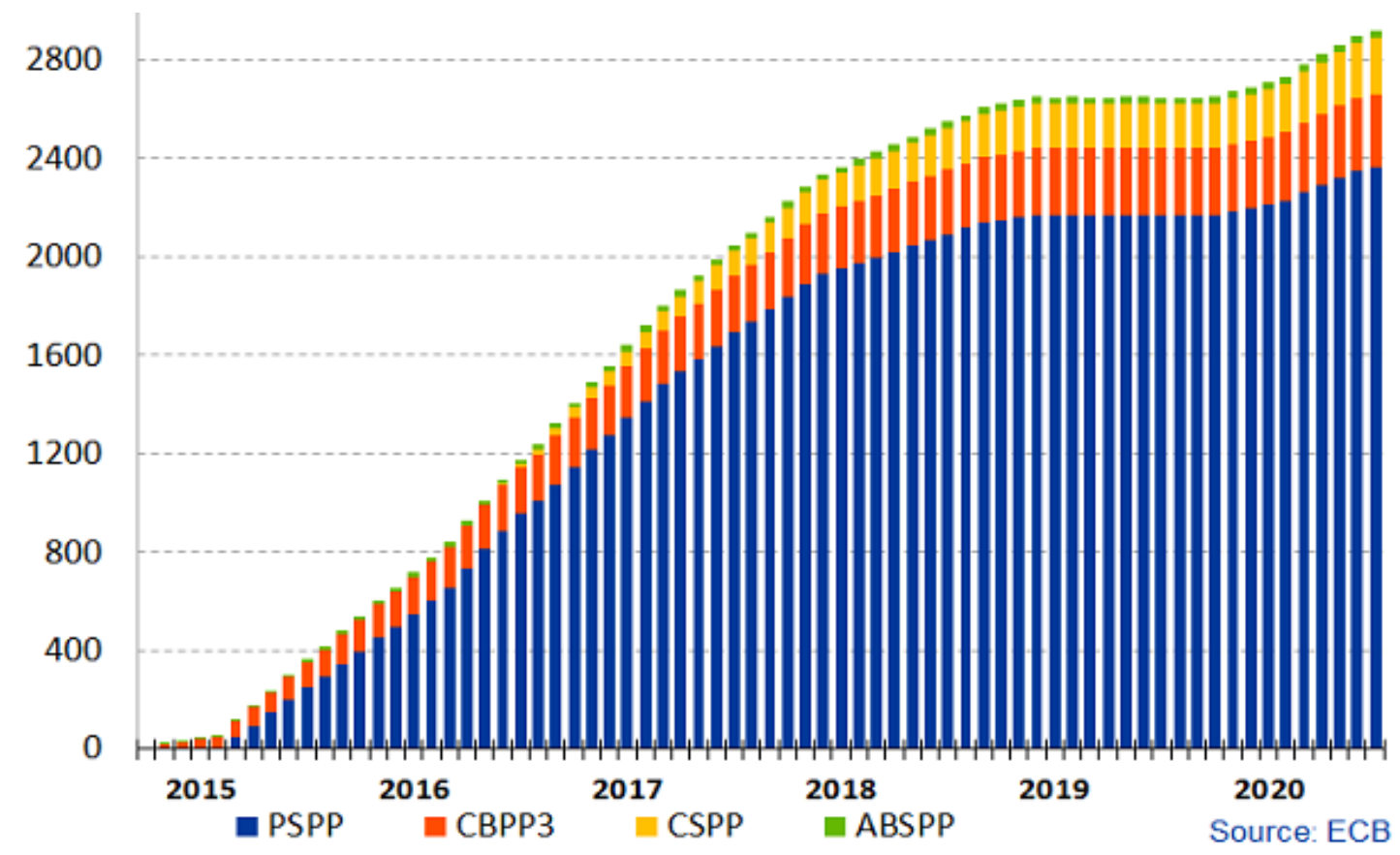

Fuente: Banco Central Europeo.

Gráfico 5. Compras de activos financieros mensuales por parte de los bancos centrales

Federal Reserve European Central Bank Bank of Japan Bank of England

Bank of Canada

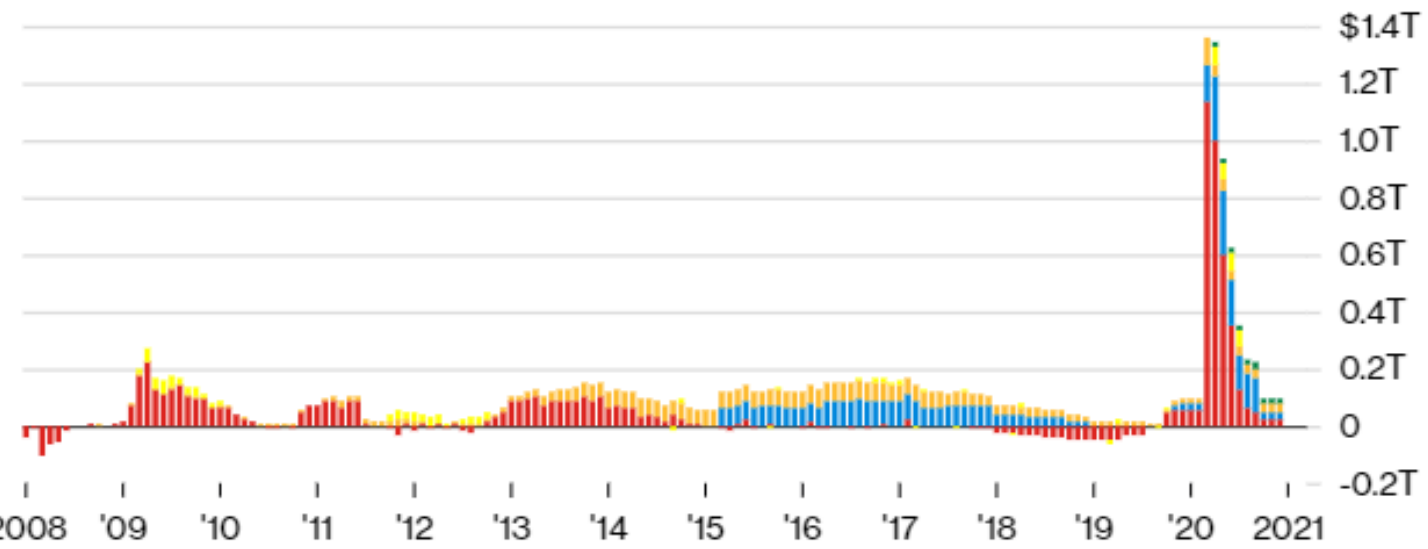

Fuente: Bloomberg.com (https://www.bloomberg.com/news/articles/2020-04-22/ecb-could-be-europe-s-back-door-to-sharing-its-debtburden).

\subsection{La protección a} España por los estímulos monetarios

Las actuaciones detalladas en el apartado anterior se suman al mantenimiento de los tipos de interés de las operaciones principales de financiación en el 0 \%, el de la facilidad de crédito en el 0,25\% y el de la facilidad de depósito en el -0,5\%, y además con una orientación clara de que van a permanecer así por mucho tiempo.

\section{Con todo ello, el BCE declara que}

«...ayudará a las empresas de toda Europa a disfrutar de un mejor acceso al crédito, impulsar la inversión, crear empleo y, por tanto, respaldar el crecimiento económico general, que es una condición previa para que la inflación vuelva y se 
Gráfico 6. Evolución de la prima de riesgo española desde el 10-9-2001 a 2-10-2020

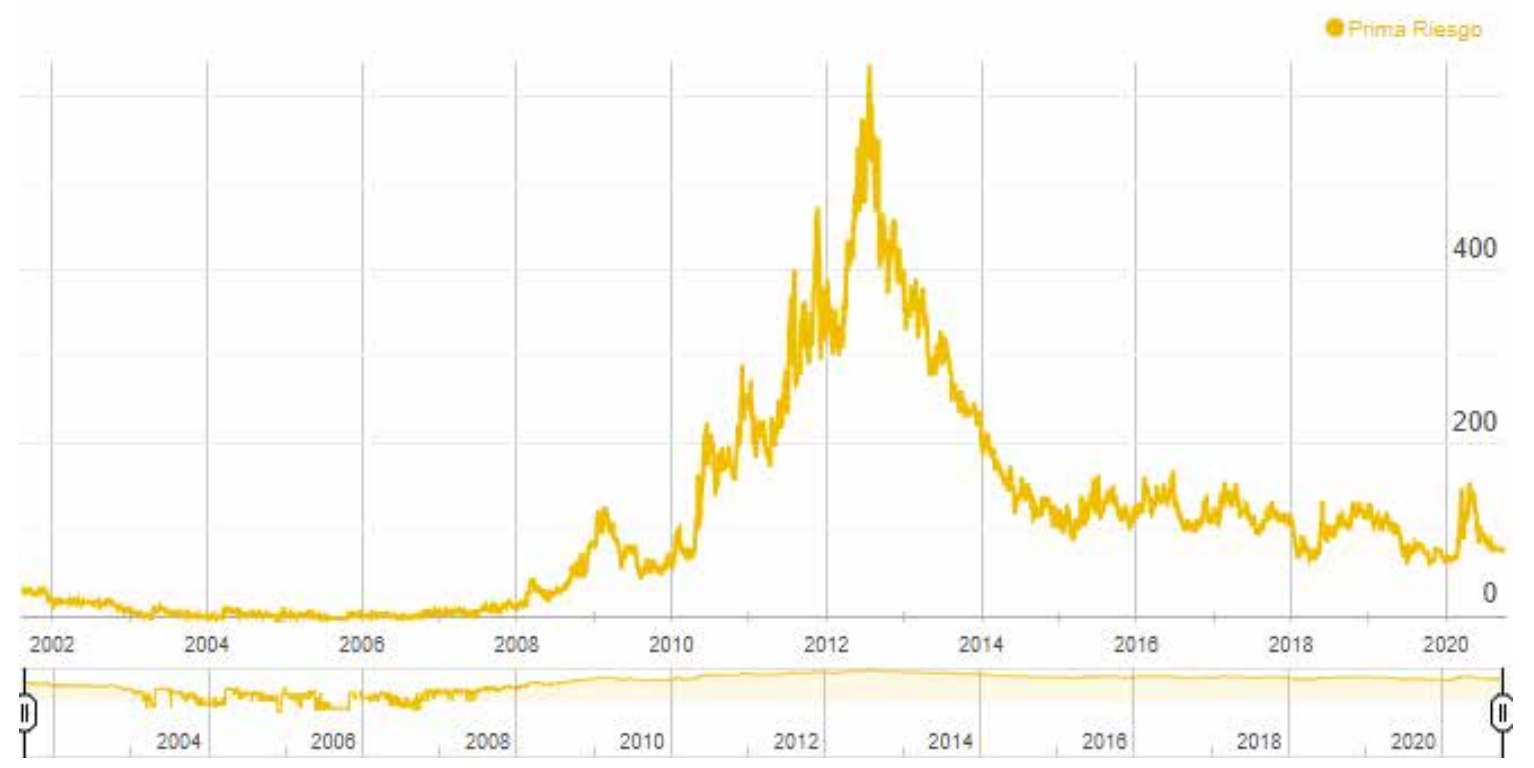

Fuente: www.datosmacro.com.

estabilice en niveles cercanos al $2 \%$. Sin perjuicio de la estabilidad de precios, estos también son objetivos importantes a los que contribuye el BCE de conformidad con el Tratado».

Para España, como para el resto de los países, estos efectos son esenciales:

- Los tipos de interés bajos ayudan a las empresas en sus cuentas de resultados con costes bajos de financiación y a las familias, especialmente a las hipotecadas, les ayudan a sobrellevar sus deudas

- El apoyo a los bancos contribuye a que puedan desarrollar su actividad prestamista y a que puedan conceder moratorias a los endeudados. Todo esto resulta vital para que no se desencadene una fatal cadena de impagos.

Pero aun siendo importantísimo lo anterior, fundamentalmente ayudan a los Estados a contener las primas de riesgo, y esto es completamente necesario para países como España. Puede acudirse también a lo ocurrido en la anterior crisis para tomar conciencia de la importancia de este apoyo.

En el gráfico 6 se observan las primas de riesgo del bono español a 10 años a lo largo del tiempo. Desde el inicio de la crisis financiera la situación se fue volviendo insosteni- ble para España, hasta alcanzar el pico que marca en 2012. Fue entonces cuando recibió el rescate financiero. Y el momento del "The ECB is ready to do whatever it takes to preserve the euro. And believe me, it will be enough», pronunciada en el verano de 2012, por Mario Draghi, el por entonces gobernador del BCE. A partir de ahí, la prima de riesgo española fue descendiendo. Puede verse también lo sucedido desde marzo de este año: el inicial repunte y el corte radical que supuso la rápida y contundente intervención del BCE.

Y para terminar de comprender lo vital que resulta para España el respaldo del BCE, el gráfico 7 señala la evolución del rendimiento del bono en estos últimos meses. Está fuera de toda lógica financiera que España pueda estar financiándose a 10 años a esos tipos de interés tan bajísimos con la gravísima situación económica por la que está atravesando: sólo se explica porque tiene un comprador -el BCE- dispuesto a comprarlo todo. 


\title{
Gráfico 7. Evolución del rendimiento del bono español a 10 años
}

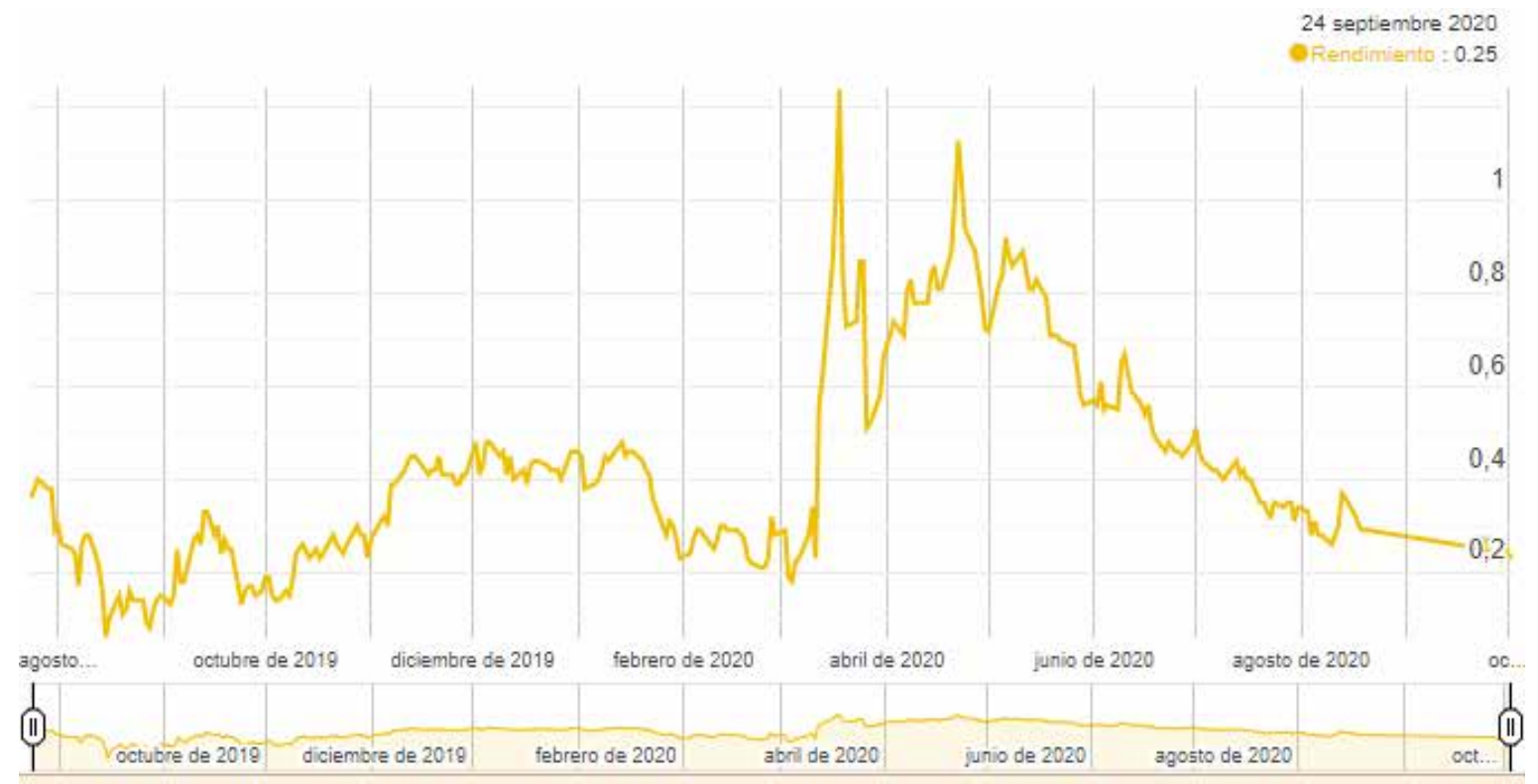

Fuente: www.datosmacro.com

\section{La respuesta fiscal}

Desde el ámbito fiscal, Europa ha respondido, también cronológicamente, en dos momentos. En primer lugar, estableció tres actuaciones, con el objetivo de contener la situación y que no se produjera un caos económico; en segundo lugar, se ha establecido una respuesta posterior mirando al futuro.

Las tres iniciativas iniciales que se pusieron en marcha fueron The European instrument for temporary Support to mitigate Unemployment Risks in an Emergency (SURE), un nuevo programa dentro del Mecanismo Europeo de Estabilidad, MEDE, y un nuevo fondo en el Banco Europeo de Inversiones, BEl: todo ello podría movilizar hasta 540.000 millones de euros.

Tras estas iniciativas, el 21 de julio, los dirigentes de la UE alcanzaron, en una reunión extraordinaria presencial en Bruselas ${ }^{5}$, un acuer-

5 Las negociaciones han sido, y siguen siendo, muy duras. Este paquete fiscal, aunque conveniente para Europa en su conjunto a largo plazo, implica una solidaridad que algunos países, los denominados frugales, se resisten a aceptar. A algunos de ellos, para que cedieran, se les han concedido mejoras dentro del presupuesto europeo. También están exigiendo fuertes controles sobre el destino de los fondos.

\begin{abstract}
do sobre una dotación presupuestaria de más de 1,82 billones de euros, que contiene el Marco Financiero Plurianual (1,0743 billones de euros) y que además contará con el apoyo en los primeros años de un fondo de reconstrucción, que ha venido a denominarse Next generation EU, por 750.000 millones de euros, que contribuirá a la reconstrucción de la UE después de la pandemia de COVID-19 y apoyará la inversión en las transiciones ecológica y digital. Las características y condiciones para la utilización y el reparto de este fondo aún se están perfilando en el Parlamento Europeo.
\end{abstract}

Tabla 2. Las medidas a causa de la pandemia

SURE/Salvaguardia de apoyo ante la crisis pandémica del MEDE/Fondo de Garantía $\quad \mathbf{5 4 0 . 0 0 0 ~ m i l l o n e s ~ E U R ~}$ del BEI para Trabajadores y Empresas

Next Generation EU

Refuerzo temporal 750.000 millones EUR
1,1 billones EUR

Fuente: Comisión Europea 
Tabla 3. Préstamos a cargo del SURE

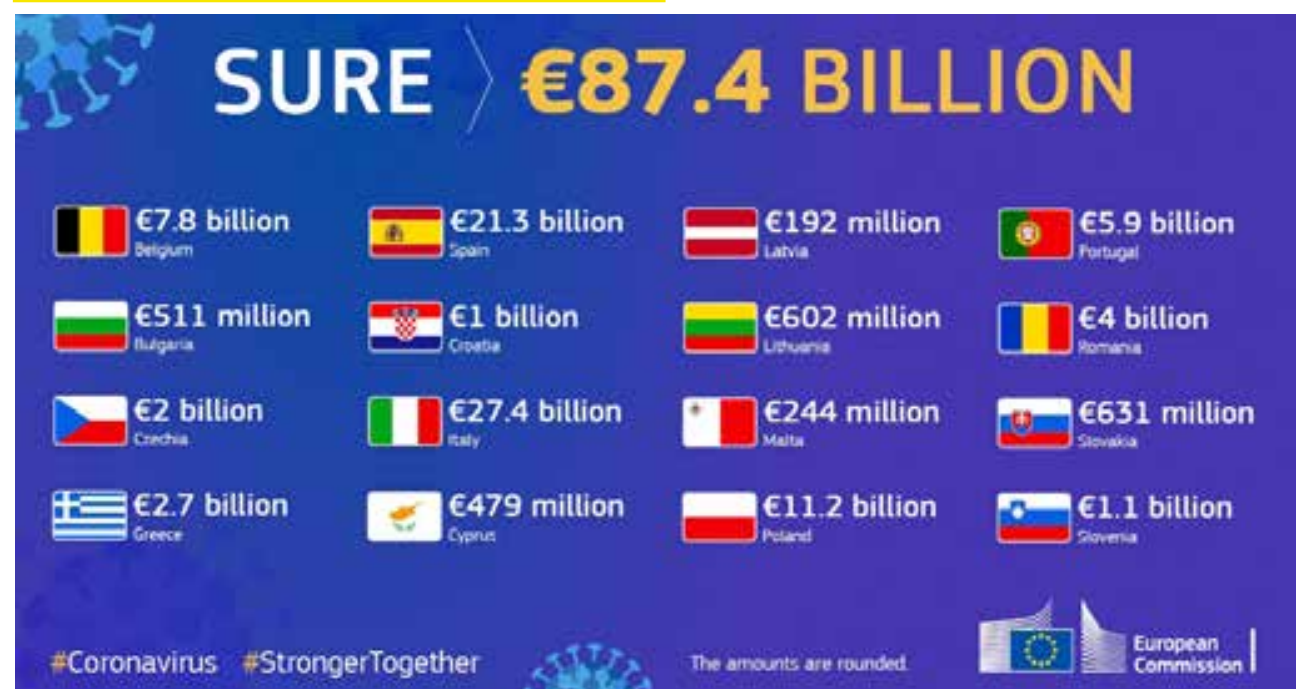

Fuente: Comisión Europea.

\subsection{SURE, MEDE y BEI}

Los tres primeros programas son de contención y cada uno tiene una finalidad distinta: proteger el empleo, ayudar en los gastos sanitarios y asegurar la liquidez de las empresas. Las dotaciones son de 100.000, hasta 240.000 y hasta 200.000 millones de euros.

Además de estas actuaciones de carácter monetario se tomaron otras regulatorias de una gran importancia. Entre ellas, la relajación de las normas europeas respecto a inversiones públicas en empresas, la suspensión del cumplimiento de las normas presupuestarias en cuanto a déficit y deuda, y la flexibilización de la utilización de los fondos estructurales.

\section{SURE}

Con este programa se pretende ayudar a los Estados miembros a abordar los aumentos repentinos del gasto público para preservar el empleo. En nuestro caso, los ERTE y las ayudas a los autónomos, entre otras intervenciones. La dotación inicial fue de 100.000 millones de euros ${ }^{6}$.

6 Los préstamos concedidos a los Estados miembros en virtud del instrumento SURE están respaldados por un sistema de garantías voluntarias de los Estados miembros. La contribución de cada uno al importe total de la garantía corresponde a su participación relativa en la renta nacional bruta (RNB) total de la Unión Europea, basada en el presupuesto de la UE de 2020. A fecha de hoy, los países han firmado ya las garantías nacionales necesarias, que en conjunto ascienden al $25 \%$ de los 100.000 millones de euros que Bruselas podrá prestar con cargo a este fondo.
Numerosos países hicieron peticiones con cargo a este programa (Bélgica, Bulgaria, Chequia, Grecia, España, Croacia, Italia, Chipre, Letonia, Lituania, Malta, Polonia, Rumanía, Eslovaquia y Eslovenia) y otros, como Portugal y Hungría, han solicitado fondos con posterioridad. Francia y Alemania no lo han hecho porque confían en que pueden financiar los costes para mantener el empleo por sí mismos. El resultado final puede verse en la tabla 3. A España le han sido asignados un total de 21.300 millones de euros?

En todos los casos se instrumentaliza mediante préstamos concedidos en condiciones favorables por la UE a los Estados miembros. Las condiciones aún no están fijadas, aunque el plazo probable de amortización se prevé que sea de 15 años.

\section{MEDE}

El Eurogrupo ha habilitado una línea de crédito por la pandemia de la COVID-19 dentro del MEDE. Esta línea de crédito permitirá a todos los países de la eurozona pedir préstamos para financiar costes sanitarios con muchas menos condiciones que los rescates que fueron instrumentalizados por esta entidad en la anterior crisis. Así, no se impondrán a los países las condiciones macroeconómicas que se exigieron entonces, como la aplicación de políticas de aus-

\footnotetext{
7 España ha gastado ya para cubrir este objetivo más de ese importe. Y este gasto seguirá creciendo por cuanto que los ERTE y otras ayudas, como a los autónomos, se han prorrogado.
} 


\section{Gráfico 8. El nuevo fondo COVID}

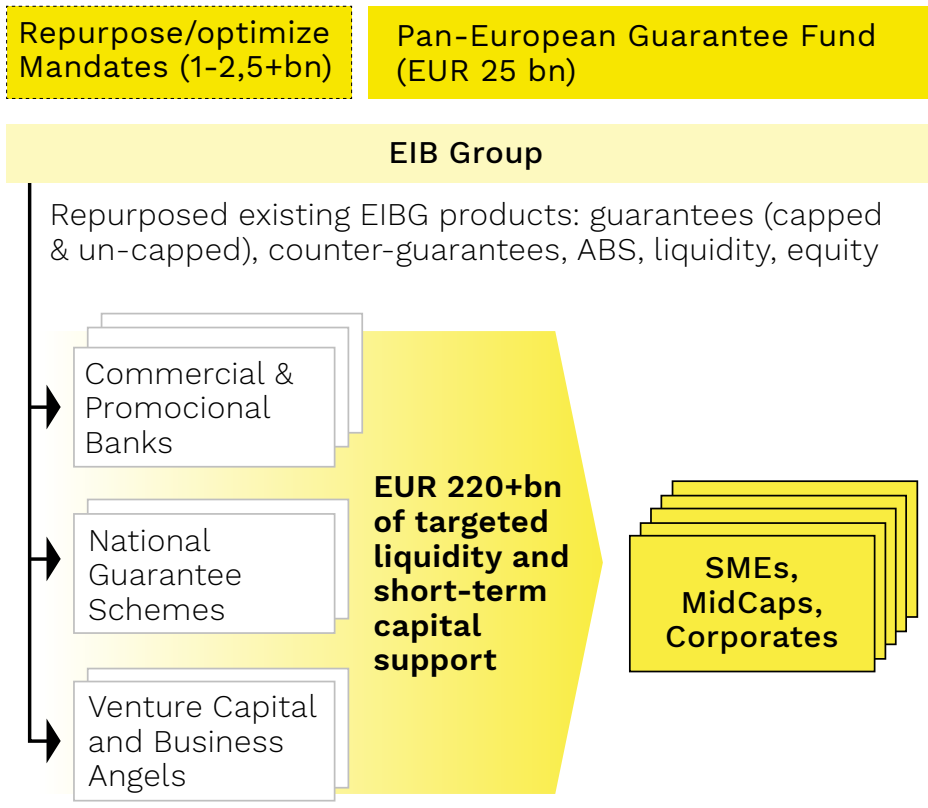

Fuente: Banco Europeo de Inversiones.

teridad o reformas estructurales. La única obligatoriedad es aplicarlos para los fines que han sido creado.

El montante máximo que podrá prestarse con cargo a esta línea es de 240.000 millones de euros. Los Estados que lo soliciten podrán recibir un préstamo del MEDE por hasta el $2 \%$ de su PIB (unos 24.900 millones de euros, en el caso del Estado español), para cubrir costes sanitarios, directos o indirectos, ligados a la crisis del coronavirus.

\section{BEI}

De forma añadida al paquete inicial de medidas - de escasa importancia- que tomó esta entidad, se crea un nuevo fondo de garantía paneuropeo por 25.000 millones de euros. El objetivo es apoyar a las pequeñas y medianas empresas (pymes) y otros beneficiarios de la economía real. En colaboración con las entidades de crédito locales y las instituciones nacionales de fomento, y mediante el apalancamiento del fondo, se espera movilizar hasta 200.000 millones de euros (ver gráfico 8). En España, entidades como el ICO o CERSA, han establecido convenios de colaboración con el $\mathrm{BEI}$ para conseguir este objetivo.

\subsection{Marco financiero plurianual y el Fondo de reconstrucción europeo}

El objetivo del fondo de reconstrucción -la iniciativa NGEU-, que apoyará al presupuesto los primeros años, es facilitar la reconstrucción postpandemia con programas de gasto alineados con las prioridades de la Unión y del presupuesto comunitario. El nuevo presupuesto a largo plazo, que incorpora en los primeros años este fondo NGEU, podría empezar a ejecutarse y a dirigir la recuperación de Europa ya desde el 1 de enero de 2021. El dinero se desembolsará por tramos y condi-

\section{Gráfico 9. Objetivos del Fondo de Reconstrucción europeo}

\section{Invertir en una Europa ecológica, digital y resiliente}

Apoyar a los Estados miembros en su recuperación

-Mecanismo de Recuperación y Resiliencia

- Ayuda a la Recuperación para la Cohesión y los Territorios de Europa (REACT-UE)

- Refuerzo de los programas de desarrollo rural

- Refuerzo del Mecanismo para una

Transición Justa

En el marco del Semestre Europeo: -Apoyo a las inversiones y las reformas

-Apoyo para una transición justa
Relanzar la economía e incitar la inversión privada

-Instrumento de Apoyo a la Solvencia

-Instrumento de Inversiones

Estratégicas

- Refuerzo del programa InvestEU

-Apoyo a los sectores y las tecnologías clave

-Inversión en las cadenas de valor clave

-Apoyo a la solvencia para empresas viables

\section{Extraer las enseñanzas de la crisis}

-Nuevo Programa de Salud

- Refuerzo de rescEU

-Refuerzo de los programas de investigación, innovación y acción exterior

-Apoyo a los programas fundamentales de cara a futuras crisis -Apoyo a los socios mundiales 
Tabla 4. Principales características del Plan de Reconstrucción de la UE

NEXT GENERATION EU (Temporal)

Compromisos hasta 2023

Desembolsos hasta 2026

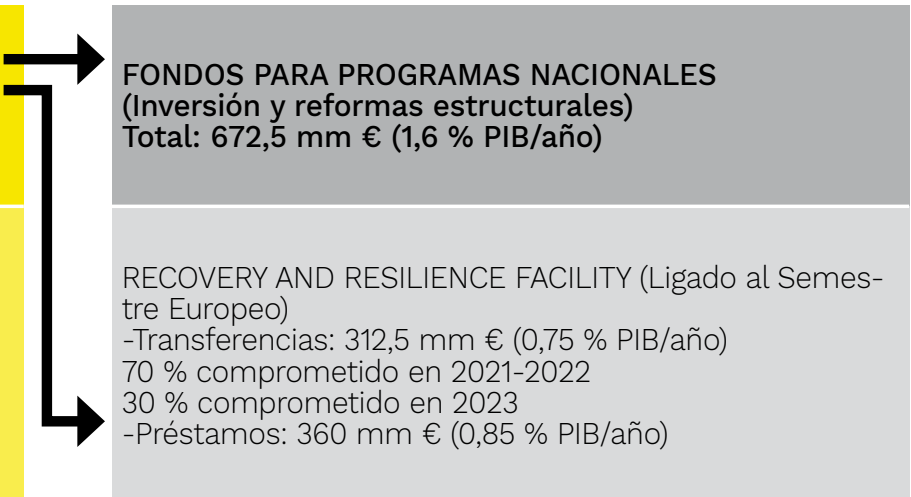

Marco Financiero Plurianual 2021-2027

FONDOS PARA PROGRAMAS PANEUROPEOS

(1,8 \% PIB/año durante 3 años)

-Transferencias y avales: $390 \mathrm{~mm} €$

-Préstamos: $360 \mathrm{~mm} €$

Financiado con deuda emitida por la CE (vencimiento hasta 2058)

Total: $77,5 \mathrm{~mm} €(0,2 \% \mathrm{PIB} / \mathrm{año})$

-React EU: Desembolso acelerado fondos de cohesión

Recursos: $47,5 \mathrm{~mm} €$

-Invest EU: Refuerzo del antiguo Plan Juncker

Recursos: 5,6 mm €

-Otros fondos: Ayuda a la innovación e investigación, transición ecológica, desarrollo rural, catástrofes

Recursos: $24,4 \mathrm{~mm} €$

Fuente: Consejo Europeo.

cionado a que se vayan cumpliendo las reformas comprometidas

El tamaño del fondo es de 750.000 millones de euros, instrumentalizado en dos categorías: 390.000 millones de euros en subsidios y el resto en préstamos. Italia y España recibirán la mayor parte de los subsidios: Italia, 81.800 millones de euros; y España, 72.700 millones de euros. Para España, los 140.000 millones entre subsidios y préstamos, supone un estímulo del $11 \%$ del PIB.

Casi el $90 \%$ de los recursos de NGEU se canalizarán a través de la llamada Facilidad de

\section{El objetivo del fondo de} reconstrucción - la iniciativa

NGEU-, que apoyará al presupuesto los primeros años, es facilitar la reconstrucción postpandemia con programas de gasto alineados con las prioridades de la Unión y del presupuesto comunitario
Recuperación y Resiliencia, dotada con 672.500 millones de euros entre transferencias a fondo perdido (312.500 millones) y préstamos (360.000), que tendrá que aplicarse conforme a las recomendaciones del Semestre Europeo. El $70 \%$ de las ayudas directas de este programa se comprometerán en los años 2021 y 2022 y el $30 \%$ restante durante 2023. Los desembolsos están previstos hasta 2026 (ver tabla 4).

Los objetivos que pretende la Comisión Europea conseguir por la aplicación del Presupuesto 2021-2027, y del refuerzo temporal que supone el NGEU, han sido ampliamente detallados por capítulos dentro de uno global, Invertir en una Europa ecológica, digital y resiliente, sustentado en tres pilares. Estos pilares son apoyar a los Estados miembros en su recuperación, relanzar la economía e incitar a la inversión privada y extraer las enseñanzas de la crisis. Su análisis excede los objetivos de este artículo8.

8 Para un mayor detalle de los objetivos del plan plurianual y del fondo de reconstrucción puede consultarse https://ec.europa.eu/info/live-work-travel-eu/health/ coronavirus-response/recovery-plan-europe es\#latest y https://www.consilium.europa.eu/es/infographics/ recovery-plan-mff-2021-2027/ 


\section{Gráfico 10. La financiación del Fondo de Reconstrucción europeo}

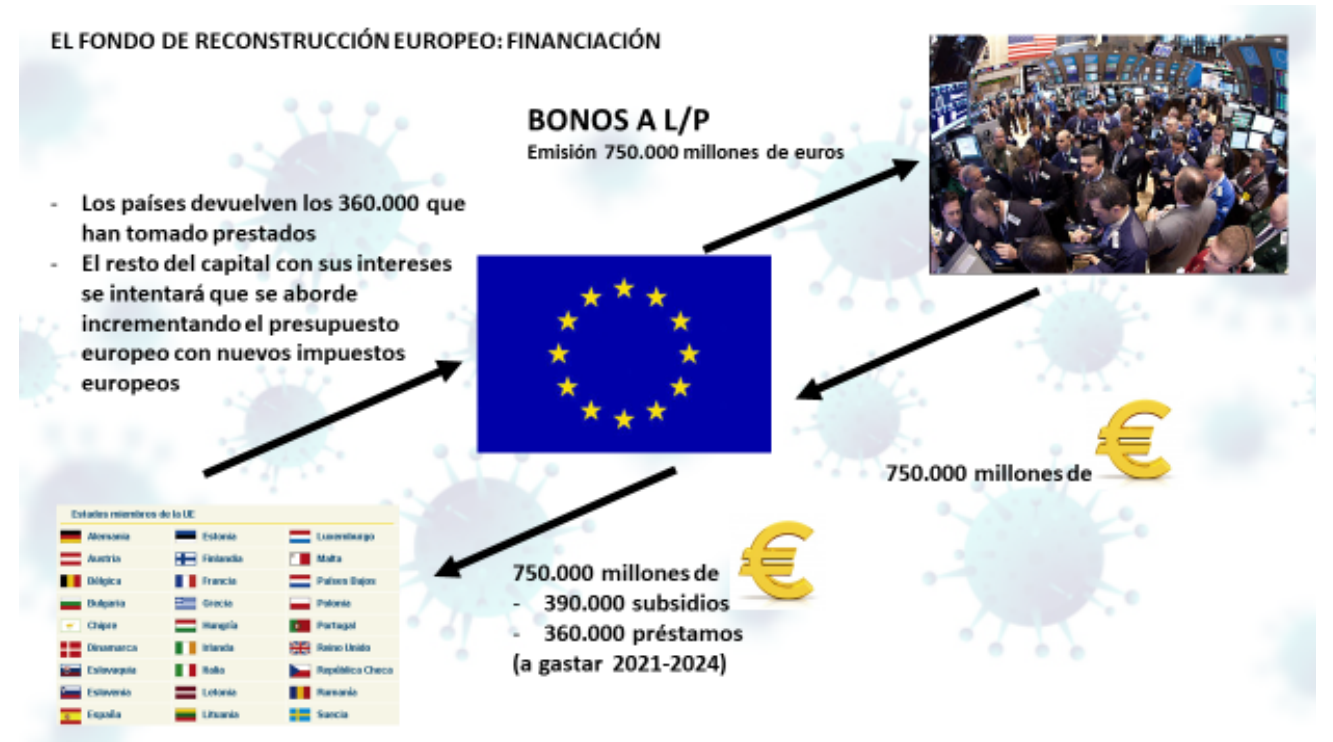

Fuente: elaboración propia.

Para la financiación del fondo (ver gráfico 10) está prevista la emisión de bonos a largo plazo (incluso se está considerando un plazo de 50 años) de forma conjunta9. Es decir, Europa se endeuda y, por tanto, queda responsable tanto de la amortización de la deuda en los plazos establecidos como de la retribución de la misma. Los 750.000 mil millones de euros obtenidos de los mercados se entregan a los diferentes Estados, bien vía préstamos bien vía subsidios, en las proporciones anteriormente reseñadas.

A su vez, Europa recaba fondos para atender las obligaciones derivadas de dicho endeudamiento por dos vías:

- Los fondos que hayan sido instrumentalizados como préstamos han de ser devueltos por los países que los han recibido en las condiciones pactadas. Esto supone recuperar en el tiempo 360.000 millones de euros, más los intereses fijados.

- El presupuesto europeo se encargará de atender la devolución y retribución de los 390.000 millones que se entregan a los Estados como subsidios. Y como se quiere evitar que se eleven las contribuciones

\footnotetext{
9 Eurobonos, aunque se ha intentado evitar este término por la gran connotación negativa que tiene debida a los enfrentamientos y conflictos que ha generado en el pasado. Se ha recalcado de forma intensa que esta emisión tiene un carácter estrictamente temporal, y que obedece a la necesidad de salir de esta crisis, pero que en ningún momento supone el establecimiento de una regularidad de endeudamiento común. Pero es bastante posible, que los eurobonos hayan venido a quedarse.
}

anuales de los países al mismo, se pretende establecer nuevos impuestos a nivel europeo: al plástico, a las emisiones de Co2, a las grandes empresas tecnológicas y a las transacciones financieras (tasa Tobin) ${ }^{10}$.

\subsection{La protección a España por los estímulos fiscales}

Haciendo una valoración global del conjunto de programas de apoyo puestos en marcha por la UE, para España resulta:

- Ha accedido al programa SURE, obteniendo un préstamo por 21.300 millones de euros.

- Tiene disponible un préstamo de hasta 24.900 millones de euros, que puede solicitar al MEDE.

- A cargo del Fondo Reconstrucción puede solicitar préstamos por un valor de hasta 67.300 millones.

En total, por tanto, España podría en los próximos años endeudarse con la UE por 113.500 millones de euros. Además, recibirá subsidios por 72.700 millones de euros ${ }^{11}$.

\footnotetext{
10 Ninguno de estos impuestos será fácil de implantar y darán mucho que hablar en los próximos meses. 11 De momento, y según lo declarado por los miembros del Gobierno, sólo se contará con el dinero del SURE y con los subsidios procedentes del Fondo de Reconstrucción.
} 


\section{Gráfico 11. Impacto de las negociaciones del Fondo de Reconstrucción europeo}

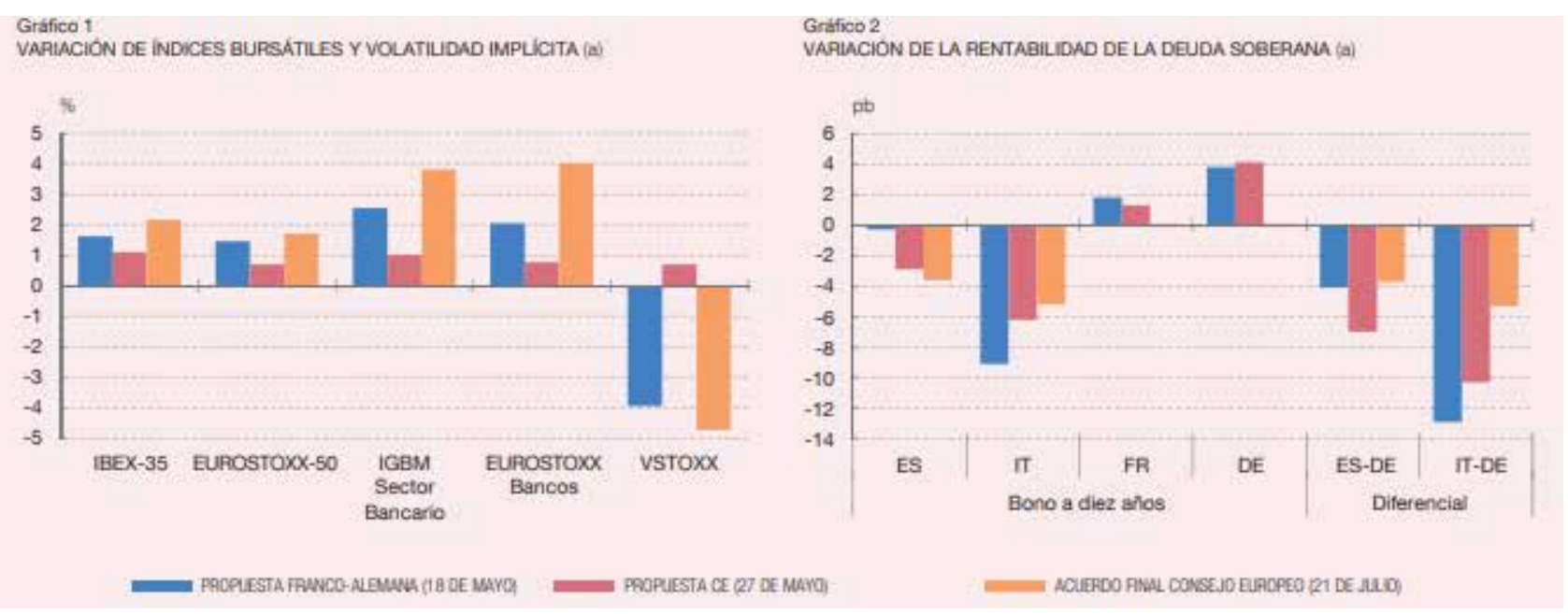

Fuente: Banco de España.

Respecto a esta ayuda, no obstante, hay que realizar las siguientes consideraciones:

- La mayor parte son préstamos, y aunque es cierto que evitan tener que acudir a los mercados en esa cantidad, lo que tensionaría la prima de riesgo, y que serán concedidos en unas condiciones de plazo y coste muy favorables, no por eso implica que no haya que devolverlos y retribuirlos.

- El plazo de recepción de los fondos estimado es muy largo: los desembolsos del fondo de recuperación se extienden hasta 2026.

- Estos fondos no son entregados para su libre disposición. Cada país debe presentar proyectos alineados a los objetivos marcados por la UE, que deberá aprobarlos de forma previa al desembolso de las cantidades. En este sentido, España ha demostrado en el pasado incapacidad para absorber los fondos que ha tenido disponibles. Va a constituir todo un reto diseñar una batería de proyectos para acaparar un montante tan enorme como el que tiene asignado ahora, y posteriormente otro reto conseguir ejecutarlos. Paralelamente, la UE vigilará que se acometan las reformas estructurales que tiene recomendadas para cada uno de los países.

Con todo, el paso dado al constituir estos estímulos es una muestra de la fortaleza de la Unión, y supone un importantísimo avance en la construcción de Europa. Nunca se había endeudado de forma conjunta en estas proporciones. Las reticencias por parte de los países del Norte a tomar deuda común habían sido cuantiosas, e insalvables hasta ahora. Pero Europa siempre ha avanzado a base de crisis. El peligro de que se pudieran desencadenar nuevos bucles perniciosos entre la deuda soberana y la banca en algunos de los países, con la posibilidad de contagio al resto, provocando una inestabilidad financiera tal que cuestionara la continuidad del proyecto europeo, ha conseguido que se superen dichas reticencias ${ }^{12}$.

Este paso dado por Europa beneficia a todos los Estados miembros a largo plazo, y en el corto, especialmente a países que parten de una situación débil en cuanto a sus finanzas públicas. Así se constata en un estudio recientemente publicado por el Banco de España ${ }^{13}$. En el gráfico 11, extraído de dicho análisis, puede observarse la mejora que experimentó el IBEX35 y el IGBM del Sector Bancario en los distintos momentos de la negociación del Fondo de Reconstrucción. También se constata la mejora en la volatilidad del mercado, y de los índices europeos Eurostoxx-50 y Eurostoxx-Bancos. Igualmente se aprecia el descenso en la rentabilidad de los bonos públicos españoles (y de los italianos) y el descenso aún mayor de su prima de riesgo, por el efecto negativo que experimenta la rentabilidad de los bonos alemanes ${ }^{14}$.

\footnotetext{
12 Fundamental también para que se diera ese paso es la situación geopolítica. Europa, ante la fragmentación del mundo en dos bloques: EE UU y China, necesita de una voz más potente y unida.

13 «NEXT GENERATION EU: PRINCIPALES CARACTERISTICAS E IMPACTO DE SU ANUNCIO SOBRE LAS CONDICIONES FINANCIERAS». Recuadro 5, dentro del Informe Trimestral de la Economía Española. Septiembre, 2020. 14 Aquí se observa bien que al menos en el corto plazo, algunos países están siendo solidarios. Justificar estos datos ante sus votantes es complicado.
} 


\section{Gráfico 12. Evolución de la deuda pública de España}

La deuda pública se sitúa en 1.289.904,6 millones de euros en junio de 2020

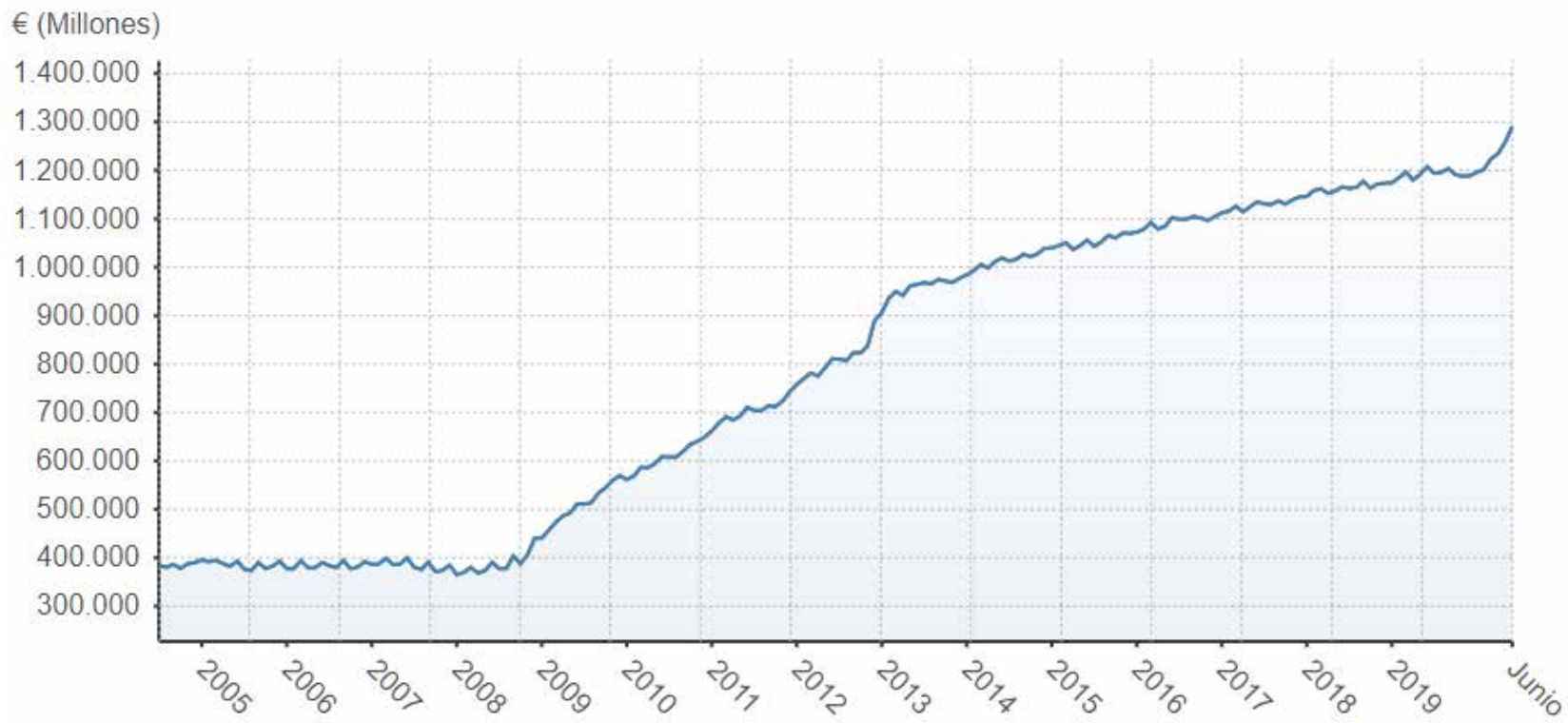

Fuente: Banco de España.

\section{4. ¿Será suficiente?}

El problema primordial con el que se encuentra España ante la crisis del COVID-19 es la mala situación de partida de sus finanzas públicas. A finales de julio de 2020 la deuda pública en España ascendía a 1.291.212,27 millones de euros. Si cuando se volvió al crecimiento después de la anterior crisis, se hubiera frenado la deuda, ahora se contaría con un colchón precioso para atender estas nuevas circunstancias adversas.

En el gráfico 12 se muestra la evolución de la deuda pública de España desde 2004. Puede apreciarse cómo desde el inicio de la crisis financiera pasada no ha dejado de crecer. También, el impacto de ésta, que pasó de casi 400.000 millones de euros en 2009 a los más de 900.000 millones en 2013. Posteriormente, aunque ha seguido al alza, los incrementos anuales han sido más moderados. De igual forma, también puede observarse el repunte desde marzo de 2020, inicio de la pandemia. En pocos meses se ha incrementado en unos 50.000 millones de euros.
Y la cuestión es: ¿cuánto más se necesitará?15 Las perspectivas macroeconómicas no son nada favorables. Las estimaciones sobre la profundidad de la caída de la actividad económica no dejan de revisarse a la baja y, lo que es peor, cada vez se alarga más el plazo previsible de recuperación y de vuelta a los niveles prepandémicos. Así, se estima, según los datos facilitados por el Gobierno el 6 de octubre, que el PIB en 2020 habrá disminuido respecto al año anterior hasta un 11,2 \%, con un rebote en 2021 del 7,2 \% (9,8 \% si se tiene en cuenta el efecto del Fondo de Recuperación), y que no se alcanzará el PIB del 2019 hasta 2024. Al respecto, la Autoridad Independiente de Responsabilidad Fiscal, AIReF, ha advertido de que estas previsiones del Gobierno serán reales siempre que se den circunstancias «favorables» en la evolución de la pandemia y en la ejecución e impacto de los fondos europeos con «máxima eficiencia» ${ }^{16}$.

15 La incertidumbre económica va ligada a la incertidumbre sanitaria. La segunda ola del virus en Europa y la intensa afectación a nivel internacional están hundiendo las previsiones. Sólo China parece haber salido de la crisis, y reforzada.

16 Según la AIReF, con la información disponible en este momento, las diferencias se deben no tanto al impacto estimado del plan como a la velocidad de la recuperación esperada que «se encuentra estrechamente ligada a las hipótesis sobre la evolución de la pandemia». 


\section{Gráfico 13. Evolución del Eurostoxx Banks}

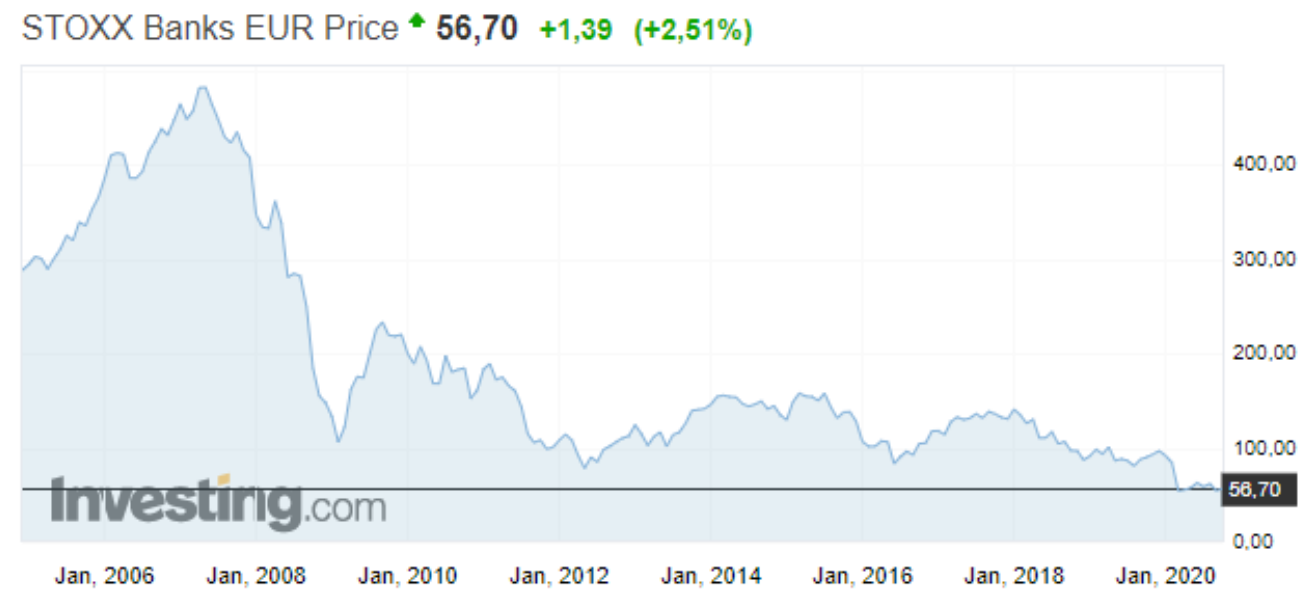

Fuente: Investing.com.

En todo caso, serán años en los que las cuentas públicas presenten déficits importantes, y al igual que la crisis pasada, la deuda pública se incrementará de forma intensa. Si atendemos a la subida de los tres años primeros de la crisis, España necesitará incrementar su deuda en 300.000 millones de euros. En este contexto, la ayuda europea resulta esencial pero insuficiente.

Ante esta situación, España corre dos riesgos de enorme importancia y que además están estrechamente relacionados. El primero es que la banca se convierta en un problema y se desencadene una crisis financiera; y el segundo es que la prima de riesgo se eleve, y que el BCE se encuentre con limitaciones para seguir sosteniéndola.

\subsection{La banca como problema}

La pandemia ha venido a agravar una situación que ya de por sí era insostenible. Los bancos no han levantado cabeza desde el inicio de la anterior crisis. Se enfrentan a un problema de rentabilidad ${ }^{17}$ que no ha hecho más que intensificarse con esta nueva crisis. El gráfico 13 detalla la evolución del Eurostoxx Banks ${ }^{18}$, reflejando la valoración que los inversores realizan de estas empresas que no consiguen una rentabilidad sobre recursos propios que compense el coste de capital.

De igual manera, el reducido valor de la ratio precio/valor contable es una muestra más de la precaria situación por la que están pasando. La ratio media de los bancos europeos se sitúa en el 0,6 y, por tanto, está muy por debajo de la ratio media de los bancos de Estados Unidos, situada en el 1,2. El mercado valora mejor a los bancos americanos porque presentan una mayor rentabilidad, con un ROE, cercano al $11 \%$, frente al 6,6 \% de los bancos europeos.

Por su parte, la banca española cotiza con un descuento sobre su valor contable del $67 \%$ en promedio. Si se divide a las entidades nacionales en dos grupos, las grandes - SANTANDER, BBVA, CAIXABANK- están cotizando en el mercado a un valor en libros de 0,40 veces, frente a las 0,18 veces de los pequeños -SABADELL, BANKIA, UNICAJA Y LIBERBANK, sin contar BANKINTER-. En el peor momento del crash, que tuvo lugar el 16 de marzo, estos múltiplos cayeron hasta las 0,3 veces y 0,15 veces, respectivamente. La tabla 5 muestra los datos de este ratio para los bancos españoles ${ }^{19}$.

\footnotetext{
17 Las causas son muchas: la herencia de la pasada crisis que todavía pesa, la intensa competencia de las Fintech y Bigtech, el desplazamiento de la financiación hacia los mercados de capitales, la sobrecapacidad, el bajo nivel de los tipos de interés...

18 En su cálculo están incluidos todos los grandes bancos españoles: BANKIA, BANKINTER, BBVA, CAIXABANK, SABADELL Y SANTANDER.
}

\footnotetext{
19 Extraído del artículo https://www.eleconomista.es/ mercados-cotizaciones/noticias/10617369/06/20/Elmercado-reconoce-solo-un-tercio-del-valor-del-activode-la-banca-cotiza-con-un-descuento-del-70.html
} 


\section{Tabla 5. Precio/Valor Contable en firmas del IBEX}

En mínimos de valoración

Valor en libros a los que cotiza la banca actualmente (veces)

\begin{tabular}{lccc} 
Compañía & Bajo & & Actual \\
Bankinter & 0,38 & 0,75 & Alto \\
Caixabank & 0,36 & 0,43 & 1,93 \\
BBVA & 0,33 & 0,42 & 6,86 \\
Banco Santander & 0,30 & 0,36 & 5,32 \\
Unicaja & 0,17 & 0,21 & 0,65 \\
Bankia & 0,07 & 0,20 & 1,51 \\
\hline Liberbank & 0,11 & 0,16 & 0,88 \\
Banco Sabadell & 0,11 & 0,13 & 2,59
\end{tabular}

Fuente: www.eleconomista.com

Y es a estas entidades, que se encuentran con respiración asistida por parte del BCE, a las que se les ha confiado ser parte de la solución. Y en la medida que se intensifique y se prolongue en el tiempo, la crisis les puede pasar una factura tal -incremento de la morosidad- que conduzca a situaciones de insolvencia. Entonces, a la crisis económica se le superpondría una financiera ${ }^{20}$. Así, el gobernador del Banco de España, Pablo Hernández de Cos, advirtió el pasado jueves, 8 de octubre, en un discurso previo a la conferencia anual de la Junta Única de Resolución (JUR) europea, que «la pandemia provocará inevitablemente problemas económicos generalizados, y la salud del sistema financiero se verá inevitablemente afectada». Además, la banca está volviendo a exponerse en mayor grado a la deuda soberana, alimentando de nuevo el círculo vicioso que el sistema financiero de la UE acusó en la última crisis de dicha deuda.

\subsection{Los límites del BCE}

A pesar del apoyo europeo, el peligro de que la prima de riesgo se tensione, elevando el coste de financiación de un altísimo volumen de deuda, existe. Todo dependerá de qué cantidad de recursos haya que recabar en los mercados financieros en los próximos años y de que la situación financiera se complique.

Como ya se comentó anteriormente, la situación de partida de las finanzas españolas es muy desfavorable. De momento, el BCE está ejerciendo de escudo protector. Y la declaración de intenciones sobre el futuro no deja lugar a dudas. Lagarde y todo el equipo que forma el Consejo de Gobierno del BCE han manifestado una y otra vez volver a hacer, como en su día hizo Mario Draghi, todo lo necesario para salvar al euro, y eso implica prestar asistencia a países como España en dónde es más probable que se complique la situación.

Pero, sin embargo, hay límites a esa ayuda incondicional que conviene tener en cuenta.
20 La anterior crisis fue inicialmente financiera y derivó en una económica, en dos olas. La de ahora ha comenzado siendo económica y puede desembocar en una financiera. 
Una política monetaria ultraexpansiva como la que se está aplicando, que se superpone a la que ya se empleó a la utilizada en la anterior crisis, puede provocar que el exceso de liquidez desencadene burbujas en los precios de los activos financieros e inmobiliarios. El BCE monitoriza de cerca está posibilidad y condiciona su toma de decisiones.

En cuanto a la inflación, de momento no constituye en absoluto un impedimento para aplicar estímulos monetarios. Pero la aplicación de estímulos fiscales a gran escala puede desencadenar alzas de la inflación. Entonces, el BCE tendría que, siguiendo su mandato, cambiar el sentido de su política monetaria. En esta línea hay que situar el cambio de estrategia de la Reserva Federal, que ha flexibilizado el objetivo de inflación señalando expresamente que permitirá que suba temporalmente por encima del $2 \%$. Es bastante probable que el BCE se añada a la reformulación de su objetivo monetario en los próximos meses.

Porque el BCE no es el único banco central que actúa. Todos lo hacen. Y lo que hagan

\section{Tabla 6. Clave de capital BCE}

\begin{tabular}{|c|c|c|}
\hline País & Clave de capital \% & Capital desembolsado $(€)$ \\
\hline Alemania & 21,4394 & 1.999.160.134,91 \\
\hline Austria & 2,3804 & $221.965 .203,55$ \\
\hline Bélgica & 2,9630 & $276.290 .916,71$ \\
\hline Chipre & 0,1750 & 16.318.228,29 \\
\hline Eslovaquia & 0,9314 & $86.850 .273,32$ \\
\hline Eslovenia & 0,3916 & $36.515 .532,56$ \\
\hline España & 9,6981 & $904.318 .913,05$ \\
\hline Estonia & 0,2291 & 21.362.892,01 \\
\hline Finlandia & 1,4939 & 139.301.721,39 \\
\hline Francia & 16,6108 & 1.548.907.579,93 \\
\hline Grecia & 2,0117 & $187.585 .027,73$ \\
\hline Irlanda & 1,3772 & $128.419 .794,29$ \\
\hline Italia & 13,8165 & $1.288 .347 .435,28$ \\
\hline Letonia & 0,3169 & 29.549.980,26 \\
\hline Lituania & 0,4707 & $43.891 .371,75$ \\
\hline Luxemburgo & 0,2679 & $24.980 .876,34$ \\
\hline Malta & 0,0853 & $7.953 .970,70$ \\
\hline Países Bajos & 4,7662 & 444.433.941,02 \\
\hline Portugal & 1,9035 & $177.495 .700,29$ \\
\hline Total $^{1}$ & 81,3286 & $7.583 .649 .493,38$ \\
\hline
\end{tabular}

Fuente: Banco de España.

Nota ${ }^{\text {: }}$ : debido al redondeo, el total puede no coincidir con la suma de todas las cifras que figuran en el cuadro. ellos puede incluso neutralizar las medidas que tome el de la eurozona. El tipo de cambio, por ejemplo, puede perjudicar enormemente a una economía que necesita recuperarse, y ese tipo de cambio está estrechamente relacionado con las medidas de política monetaria. Sólo hay que acudir al debate que ha estado sobre la mesa en la última reunión del Consejo de Gobierno del BCE de 10 de septiembre a causa del debilitamiento del dólar.

Si se desatara una guerra de divisas, empujaría al BCE a intensificar más y más los estímulos. De hecho, se cuestionó en la última reunión que se debería haber ampliado 500.000 millones más las compras de activos o bajar aún más los tipos de interés para contestar a esa apreciación del euro respecto al dólar. De momento, el BCE ha preferido no entrar en esta dinámica.

Ante este escenario, las disputas internas en el Consejo de Gobierno, entre las «palomas» - países favorables a los estímulos - y los «halcones» - países que quieren ser muy comedidos en cuanto a la política monetaria-, se dispararán. Son desavenencias que vienen de lejos y que se han agudizado con las medidas tomadas en la pandemia. La reciente sentencia del Tribunal alemán en contra del programa APP, exigiendo que se demostrara su necesidad y proporcionalidad, es una muestra clara de esa discrepancia ${ }^{21}$.

Además, el nuevo programa, el PEPP, ha nacido con una flexibilidad de la que muchos países reniegan. Lo más peliagudo que presenta es la posibilidad de saltarse la clave de capital. La clave de capital es la proporción en la que cada país contribuye al capital del banco central (ver tabla 6). Las participaciones de los bancos centrales nacionales en este capital se calculan utilizando la participación de

21 Parece que los jueces alemanes han olvidado que las naciones de la Eurozona no tienen poder para cuestionar lo que se decide respecto a la política monetaria. Hay que recordarles que cedieron soberanía a una entidad supranacional e independiente para que actuara con total autonomía en este aspecto. El BCE no se ha inmutado y se ha limitado a comunicar escuetamente que toma nota, pero que seguirá haciendo todo lo necesario. O sea, que piensa seguir con dicho programa, con el nuevo -el Pandemic emergency purchase programme (PEPP) - , con el resto de medidas que ha adoptado, y lo que haga falta. También podría haber aclarado a los alemanes que mientras que pertenezcan al club, el Bundesbank tendrá que hacer lo que se le ordene, porque en política monetaria es sólo la sucursal operativa que tiene en ese territorio europeo. 
Tabla 7. Volumen de compras bajo el PEPP por países

$\begin{array}{lcccc}\begin{array}{l}\text { Book value as at } \\ \text { end-September 2020 } \\ \text { (EUR millions) }\end{array} & \begin{array}{l}\text { Net purchases } \\ \text { August-September } \\ \text { 2020 }\end{array} & \begin{array}{l}\text { Cumulative net } \\ \text { purchases as at end- } \\ \text { September 2020* }\end{array} & \begin{array}{l}\text { Current WAM } \\ \text { of public sector } \\ \text { securities holdings } \\ \text { under the PEPP* }\end{array} & \begin{array}{l}\text { WAM of eligible } \\ \text { universe of public } \\ \text { sector securities } \\ \text { under the PEPP as } \\ \text { at end-September } \\ \text { 2020** }\end{array} \\ \text { Austria } & & & 10,93 & 7,16 \\ \text { Bélgica } & 3.558 & 13.614 & 5,93 & 9,44 \\ \text { Chipre } & 4.426 & 17.279 & 11,66 & 8,10 \\ \text { Alemania } & 257 & 1.194 & 4,51 & 6,63 \\ \text { Estonia } & 32.033 & 125.048 & 9,62 & 7,67 \\ \text { España } & 29 & 192 & 8,37 & 7,01 \\ \text { Finlandia } & 14.918 & 61.030 & 7,34 & 7,37 \\ \text { Francia } & 2.232 & 8.688 & 9,04 & 9,13 \\ \text { Grecia } & 24.817 & 84.237 & 8,32 & 9,63 \\ \text { Irlanda } & 3.020 & 12.966 & 8,34 & 6,80 \\ \text { Italia } & 2.057 & 8.028 & 6,96 & 10,61 \\ \text { Lituania } & 21.811 & 95.243 & 12,01 & 6,36 \\ \text { Luxemburgo } & 395 & 1.988 & 6,37 & 8,89 \\ \text { Letonia } & 187 & 994 & 9,72 & 7,91 \\ \text { Malta } & 50 & 837 & 7,56 & 7,23 \\ \text { Países Bajos } & 114 & 238 & 3,92 & 6,63 \\ \text { Portugal } & 7.121 & 27.795 & 7,04 & 8,56 \\ \text { Eslovenia } & 2.844 & 11.649 & 7,03 & 8,07 \\ \text { Eslovaquia } & 585 & 2.481 & 6,80 & 7,23 \\ \text { Supranationals } & 547 & 4.338 & 8,06 & 7,20 \\ \text { Total } & 5.831 & 33.811 & 6,89 & \end{array}$

Fuente: Banco Central Europeo.

los respectivos países en la población y en el producto interior bruto de la UE. Estos dos factores tienen igual peso a efectos de dicho cálculo.

Las compras de activos financieros deberían realizarse respetando estas proporciones, pero este programa nace con la posibilidad de saltárselas. Es decir, que se compre más deuda pública de alguno de los países para ayudarles especialmente si lo necesitan. Hasta ahora el volumen de compras de deuda pública de cada uno de los países se muestra en la tabla 7. De momento, los porcentajes se están cumpliendo ${ }^{22}$.

A pesar de esa autorización con la que cuenta el programa PEPP, si en la realidad se plasman estas diferencias, el conflicto puede desatarse. España e Italia son los principales candidatos para que el BCE se tenga que volcar con ellos ya que el impacto del virus -económica y sanitariamente- ha sido mayor y su situación financiera de partida mucho más débil. El resto de países puede oponerse a seguir ampliando el volumen alegando que ayudar a determinados Estados por la puerta falsa está prohibido por los Tratados de la Unión. De momento, han pesado más las ventajas de permanecer unidos que los intereses particulares: ¿hasta cuándo? 



\section{2

\section{NÚMEROS PUBLICADOS}

55: Gestión del pluralismo religioso en el ámbito autonómico y local

56: La educación como factor determinante de la movilidad intergeneracional en Andalucía

57: Las compañías de bajo coste en los aeropuertos andaluces

58: La construcción del sujeto político entre los jóvenes en riesgo

59: La disposición a pagar por el medio ambiente. Un análisis con datos de Andalucía

60: La inmigración en Andalucía. Un análisis con datos de la Seguridad Social en 2009

61: Percepción de la desigualdad y demanda de políticas redistributivas en Andalucía

62: Las violencias masculinas y la prevención de la violencia contra las mujeres

62: Las violencias masculinas y la prevención de la violencia contra las mujeres

63: La población infantil ante las nuevas tecnologías de la información. Una aproximación a la realidad de los nativos digitales andaluces

64: El contacto de la ciudadanía con los ayuntamientos como forma de participación política en Andalucía

65: Hacia un modelo de movilidad urbana sostenible

66: Las transiciones hacia el empleo de la juventud andaluza

67: El sector de los alimentos ecológicos en Andalucía: diagnóstico, retos y estrategias

68: Percepción de los españoles y andaluces ante la pobreza

69: La presencia de las mujeres en los ayuntamientos andaluces (1979-2011)

70: Un relato sobre identidad y vida buena en Andalucía

71: Bienestar, desigualdad y pobreza en Andalucía: un estudio comparativo con el resto de España a partir de las encuestas de condiciones de vida 2006 y 2012
72: Competencias autonómicas y gestión de la cuenca del Guadalquivir

73: Reformas legislativas, incumplimientos de la Carta Social Europea y su invocación en los órganos judiciales

74: Reforma constitucional y nuevo paradigma del Estado social. De la ordenación contingente a la organización consciente del bienestar

75: Bullying, cyberbullying y dating violence. Estudio de la gestión de la vida social en estudiantes de Primaria y Secundaria de Andalucía

76: ¿Odiamos la política?

77: Determinantes sociales de la salud en Andalucía

78: Líderes políticos y calendario electoral. Un análisis de la percepción de la población andaluza

79: La Renta Mínima de Inserción en Andalucía. Alcance y limitaciones

80: La edición independiente en Andalucía

81: Género y movilidad social: nuevos datos para Andalucía

82: Cambios en el comportamiento electoral en Andalucía. Análisis del ciclo electoral 2018-2019 (autonómicas, generales y municipales)

83: La cohesión territorial a través de la identidad nacional. El bienestar como elemento vertebrador de España

84: Brechas y sesgos de género en la elección de estudios STEM. ¿Por qué ocurren y cómo actuar para eliminarlas?

85: El reto de la longevidad en Andalucía. Causas, evolución y consecuencias

86: Nuevas tendencias en la vertebración de Andalucía. Territorio, población y familia en el siglo XXI

87: Democracia vs. desinformación. Propuestas para la protección de las sociedades abiertas

88: La crisis del coronavirus y la economía andaluza. Impacto, tendencias y recomendaciones

89: La respuesta de Europa a la crisis. ¿Está España protegida? 
